\title{
RADIOCARBON DATING PROBLEMS USING ACETYLENE AS COUNTING GAS
}

\author{
MEBUS A GEYH \\ Niedersächsisches Landesamt für Bodenforschung \\ D-3000 Hannover, Federal Republic of Germany
}

\begin{abstract}
An investigation of inconsistent Hannover results in the International Collaborative Study (ICS) led to the conclusion that the main reason was contamination of the acetylene used as counting gas with recent and/or fossil carbon by the lithium used for its preparation. Despite the high level of purity of the lithium guaranteed by the producer and storage under argon in cans, different charges were partly covered with contemporary lithium carbonate and fossil oil sometimes was used to preserve the metal. Thorough cleaning of the surface of the lithium rods decreased the contamination but did not remove it entirely, which is evidenced in the wider scatter of the counting rates of various background gases than that of radiocarbon-free tank acetylene. As a result of the high risk of contamination with fossil and/or recent carbon from the acetylene counting gas, the high price of lithium, and the time-consuming preparation, the Hannover ${ }^{14} \mathrm{C}$ Laboratory will use carbon dioxide instead of acetylene as counting gas in the future.
\end{abstract}

\section{INTRODUCTION}

As early as the 1960 s, we found decreased reproducibility of ${ }^{14} \mathrm{C}$ determinations for small samples when acetylene was used as counting gas, resulting from contamination with up to $3 \mathrm{mg}$ $\mathrm{C} / \mathrm{g}$ lithium used in preparation (Geyh 1969). The German factory, Metallgesellschaft $\mathrm{GmbH}$, Frankfurt, was unable to produce this metal without using paraffin oil for protection. An English factory delivered lithium completely embedded in paraffin wax, with the same result.

The contamination problem was solved by cleaning the rods with dilute hydrochloric acid. However, this procedure was quite dangerous and could be done only under a fume hood. After a lithium fire ignited, we terminated this cleaning process. Fortunately, we learned of pure lithium rods and shot produced by LITHOCA, Inc, USA, which are delivered in argon-filled cans and guaranteed to be free of carbon contamination. The use of both this substance, and the cleaning procedure, yielded the theoretically expected reproducibility for at least ten years.

In the early 1980s, high-precision dating of tree rings of German oak logs by the Heidelberg ${ }^{14} \mathrm{C}$ Laboratory, which we dated several years ago, showed that ca $5 \%$ of our results were up to 300 years too old. The results of Hans Suess, who also used acetylene as counting gas for his treering analyses, were comparable with ours. He withdrew a similar percentage of his ${ }^{14} \mathrm{C}$ dates that were wrong (pers commun). This could only happen if time series of tree rings or archaeological samples of rather accurately known ages are dated which show unquestionable outliers. All our experiments to find the source of error were unsuccessful.

\section{RESULTS OF STAGES 1 AND 2 OF THE ${ }^{14} \mathrm{C}$ ICS}

The results of the International Study Group (1982) confirmed the earlier finding of outliers. Figure $1 \mathrm{~A}$ shows the results of the Hannover ${ }^{14} \mathrm{C}$ Laboratory. The results of the first five samples are in satisfactory agreement with the mean values of the Interlaboratory Comparison. The three other results are outliers. The samples for the last three were prepared by an unskilled technician. The chemical records describe difficulties in burning these samples. However, attempts to reproduce these variations were unsuccessful.

It was quite interesting that the external error multipliers for ${ }^{14} \mathrm{C}$ laboratories using $\mathrm{CO}_{2}$ and benzene differed by 1.23 and 2.3, respectively. This gave us the first hint that the preparation of hydrocarbons may be a source of irreproducible results. 


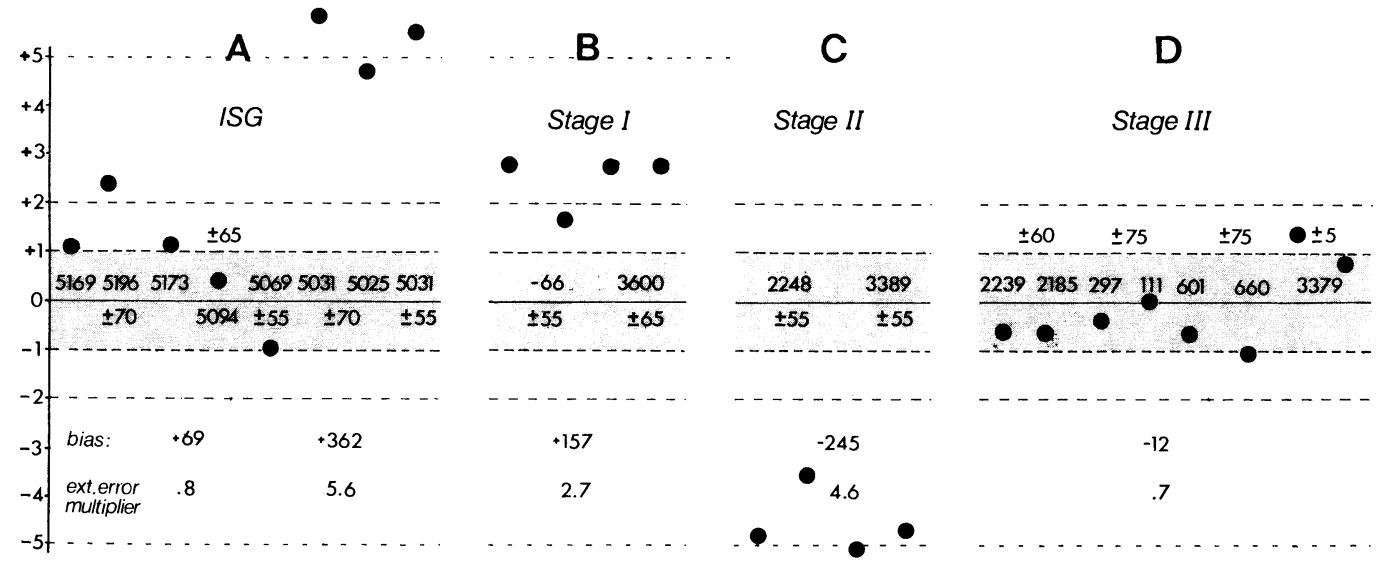

Fig $1 .{ }^{14} \mathrm{C}$ results of the Hannover ${ }^{14} \mathrm{C}$ Laboratory for the Interlaboratory Comparison - International Study Group (1982) (A), for Stage 1 of ICS (B), for Stage 2 (C), and for Stage 3 (D). The external error multipliers are given without bias correction and refer to the mean of all results assuming a zero standard deviation.

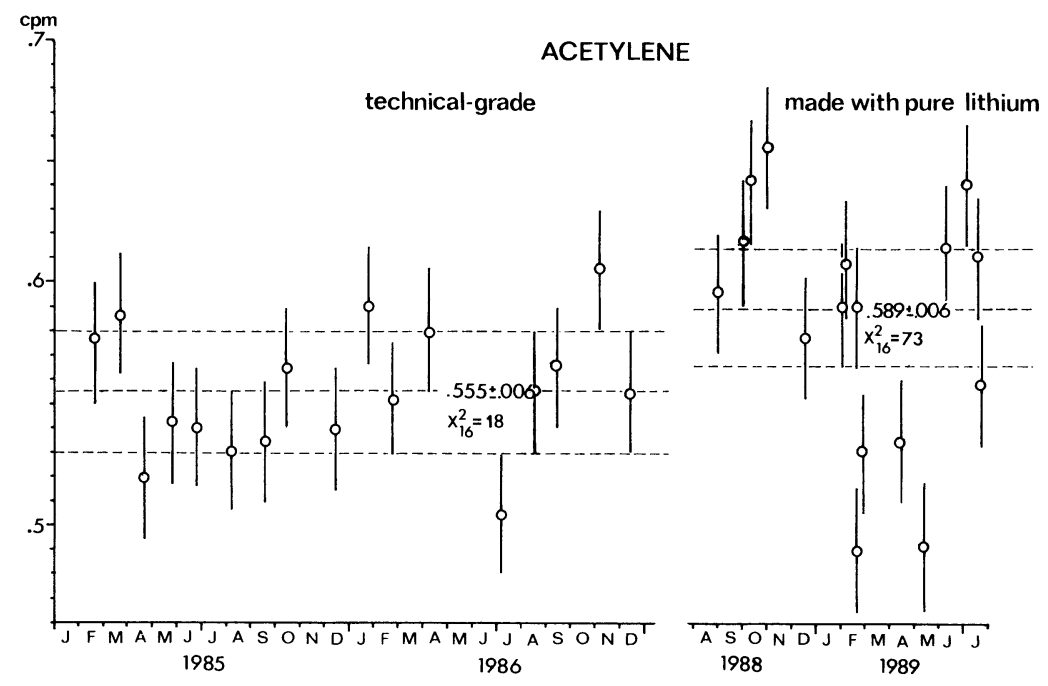

Fig 2. Scatter of the ${ }^{14} \mathrm{C}$ background counting rate in $1985 / 1986$, using technical-grade acetylene prepared from fossil natural carbon sources as counting gas, and in mid-1988/1989 using acetylene produced from pure lithium rods that were mecl.anically cleaned.

Figure $1 \mathrm{~B}, \mathrm{C}$ shows conventional ${ }^{14} \mathrm{C}$ data of the Hannover ${ }^{14} \mathrm{C}$ Laboratory and mean values of all laboratories of Stages 1 and 2. Our results for Stage 1 were barely satisfactory, but those of Stage 2 were very poor. Contamination with up to $3 \%$ contemporary carbon could have explained the deviation. The search for the reason was partially successful. We used an incorrect internal standard in Stage 2. However, further experimentation strongly reconfirmed arguments for lithium-derived contamination. 


\section{CONTAMINATION EXPERIMENTS WITH LITHIUM}

During experiments on this kind of contamination, the chemical technicians reported visual differences in the quality of the lithium rods in different cans. At times, the lithium smelled of oil. At other times, the usually dark-gray rods were partly covered with a white layer. Apparently, LITHOCA, Inc had some difficulties producing pure lithium. The technicians did not record these observations because they were unaware of the original lithium contamination experiments (Geyh 1969).

We first prepared lithium carbide from fossil $\mathrm{CO}_{2}$ to exclude memory effects. For the hydrolysis, we used $1.5 \mathrm{~L} \mathrm{H} \mathrm{H}_{2} \mathrm{O}$ containing no $\mathrm{CO}_{2}$ and with $62 \mathrm{mg} / \mathrm{L} \mathrm{C}$ with a ${ }^{14} \mathrm{C}$ content of 57.2 pMC. The ${ }^{14} \mathrm{C}$ content of the acetylene corresponded to background in both cases. But the ${ }^{14} \mathrm{C}$ content of inorganic carbon compounds dissolved in the lithium hydroxide solution was 94 pMC (Table 1, No. 1) and 16.4 pMC (Table 1, No. 2). Evidently, contemporary and fossil carbon may be introduced during the hydrolysis. There seems to be no transfer of ${ }^{14} \mathrm{C}$ from the carbon compounds in the lithium hydroxide to the acetylene. Thus, the counting gas is not contaminated during hydrolysis.

Control experiments with apparently pure lithium heated to ca $600^{\circ} \mathrm{C}$ without using $\mathrm{CO}_{2}$ yielded acetylene corresponding to a maximum of $0.6 \mathrm{mg} \mathrm{C} / \mathrm{g}$ lithium (Table 1, Nos. 3-5). During routine preparation, we use $25 \mathrm{~g} \mathrm{Li}$ for samples containing ca $3 \mathrm{~g}$ carbon. Thus, pure lithium may cause contamination of ca 5\%. The same experiment with unheated pure lithium yielded a carbon content ten times higher in the lithium hydroxide solution with ${ }^{14} \mathrm{C}$ activity at $72.3 \mathrm{pMC}$.

TABLE 1

${ }^{14} \mathrm{C}$ results of lithium contamination experiments with fossil carbon dioxide

\begin{tabular}{|c|c|c|c|c|c|c|c|c|}
\hline \multirow{3}{*}{ No. } & \multicolumn{2}{|c|}{$\mathrm{CO}_{2}$} & \multicolumn{2}{|c|}{$\mathrm{LiOH}$} & \multicolumn{3}{|c|}{$\mathrm{C}_{2} \mathrm{H}_{2}$} & \multirow{3}{*}{ Remarks } \\
\hline & \multicolumn{2}{|c|}{ Quantity } & Quantity & Activity & Yield & Activity & Quantity & \\
\hline & $\begin{array}{c}\mathrm{C} / \mathrm{CO}_{2} \\
\mathrm{~g}\end{array}$ & $\begin{array}{l}\mathrm{Li} \\
\mathrm{g}\end{array}$ & $\begin{array}{c}\mathrm{C} \\
\mathrm{mg} / \mathrm{L}\end{array}$ & $\mathrm{pMC}$ & $\%$ & & $\mathrm{mg}$ & \\
\hline 1 & 2.06 & 23 & 126 & 94.0 & 89 & $<.5$ & - & $600^{\circ} \mathrm{C}$ \\
\hline 2 & 1.74 & 22 & 52 & 16.4 & 96 & $<.5$ & - & $600^{\circ} \mathrm{C}$ \\
\hline 3 & 0 & 25 & 7.1 & - & - & - & 15 & $600^{\circ} \mathrm{C}$ \\
\hline 4 & 0 & 25 & 67.9 & 72.3 & - & - & 1 & $\begin{array}{l}\text { Old can, } \\
\text { no heat }\end{array}$ \\
\hline 5 & 0 & 25 & 11.5 & - & - & - & 1 & $\begin{array}{c}\text { New can, } \\
\text { no heat }\end{array}$ \\
\hline
\end{tabular}

Obviously, there are two sources of contamination. If the cans are not completely tight, argon leaks out and air enters the cans, forming contemporaneous lithium carbonate. This $\mathrm{Li}_{2} \mathrm{CO}_{3}$ decomposes during heating of the lithium, partly forming lithium carbide, which converts to acetylene. The other source of contamination is oil, resulting in contamination by fossil carbon.

${ }^{14} \mathrm{C}$ results of Stages 1 and 2 of the ICS reflect these two sources of contamination. We observe positive deviations from the mean in Stage 1 (contamination by fossil carbon), and negative in Stage 2 (contamination by contemporary carbon). 
After these experiments, we resumed thorough cleaning of the lithium rods from LITHOCA, Inc. The surface was mechanically cleansed until it became a shining silver color. We needed no more than a few minutes for each sample with this procedure. Figure $1 \mathrm{D}$ shows the ${ }^{14} \mathrm{C}$ results of Stage 3 of the ICS which now agree well with the mean.

These apparently satisfactory results still indicate contamination on the order of a few per mil. Figure 2 shows the scatter of the background counting rate for one of our Oeschger counters. We measured technical-grade acetylene as background gas, prepared from natural gas, in 1985/1986. The scatter of the dates corresponds to the standard deviations using Poisson statistics. We have produced background acetylene from fossil $\mathrm{CO}_{2}$ and mechanically cleaned lithium since mid-1988. The scatter increased by a factor of 2 . We explain this by residual contamination of the lithium metal on the order of a few per mil. We have been unsuccessful at further attempts to improve the results. We will next use lithium rods individually wrapped in argon-filled plastic tubes, available from LITHOCA, Inc (R Beukens, pers commun).

As the external error multipliers of laboratories using hydrocarbons appear to be still higher than those of laboratories using $\mathrm{CO}_{2}$ as counting gas, the problems may be partly due to carbon contamination by lithium.

\section{CONCLUSION}

We conducted experiments on carbon contamination by lithium owing to the unsatisfactory agreement of the ${ }^{14} \mathrm{C}$ results of the Hannover ${ }^{14} \mathrm{C}$ Laboratory during Stages 1 and 2 of the ICS. The results confirmed our suspicions. We found mechanical cleaning of the rods to be essential in removing the major sources of contamination. However, complete decontamination was not yet possible. Perhaps we can overcome this problem by changing the counting gas. If we use proportional gas counters, $\mathrm{CO}_{2}$ seems to be the best alternative for which very simple purifying procedures are required (Jelen \& Geyh 1986; Dörr, Kromer \& Münnich 1989).

\section{ACKNOWLEDGMENTS}

Thanks go to my friend Bernd Becker, who provided precisely dated tree-ring material for our contamination experiments in the 1980 s. We also appreciate the high-precision ${ }^{14} \mathrm{C}$ dates provided by Bernd Kromer of the Heidelberg ${ }^{14} \mathrm{C}$ Laboratory. Dr G-J Hennig guided the technical team of the Hannover ${ }^{14} \mathrm{C}$ Laboratory during the lithium contamination experiments.

\section{REFERENCES}

Dörr, H, Kromer, B and Münnich, KO 1989 Fast ${ }^{14} \mathrm{C}$ preparation of organic material. In Long, A and Kra, RS, eds, Internatl ${ }^{14} \mathrm{C}$ conf, 13th, Proc. Radiocarbon 31(3): 264-268.

Geyh, MA 1969 Problems in radiocarbon dating of small samples by means of acetylene, ethane and benzene. Internatl Jour Appl Radiat Isot 20: 463-466.

International Study Group 1982 An inter-laboratory comparison of radiocarbon measurements in tree rings. Nature 298: 619-623.

Jelen, K and Geyh, MA 1986 A low-cost miniature counter system for radiocarbon dating. In Stuiver, M and Kra, RS, eds, Internatl ${ }^{14} \mathrm{C}$ conf, 12th, Proc. Radiocarbon 28(2A): 578-585. 